F. Willem Rozendaal

Peter E. Spronk

Ferdinand F. Snellen

Adri Schoen

Arthur R. H. van Zanten

Norbert A. Foudraine

Paul G. H. Mulder

Jan Bakker

On behalf of the other UltiSAFE

investigators

\section{Remifentanil-propofol analgo-sedation shortens duration of ventilation and length of ICU stay compared to a conventional regimen: a centre randomised, cross-over, open-label study in the Netherlands}

Received: 19 December 2007

Accepted: 17 September 2008

Published online: 24 October 2008

(C) The Author(s) 2008. This article is published with open access at Springerlink.com

Electronic supplementary material The online version of this article (doi:10.1007/s00134-008-1328-9) contains supplementary material, which is available to authorized users.

F. W. Rozendaal

Jeroen Bosch Hospital, 's-Hertogenbosch,

The Netherlands

P. E. Spronk

Gelre Hospitals, Apeldoorn,

The Netherlands

F. F. Snellen

Isala Clinics, Zwolle, The Netherlands

A. Schoen

Rivierenland Hospital, Tiel,

The Netherlands

A. R. H. van Zanten

Gelderse Vallei Hospital, Ede,

The Netherlands

N. A. Foudraine

VieCuri Medical Centre North-Limburg,

Venlo, The Netherlands
P. G. H. Mulder · J. Bakker (®) Department of Intensive Care, Hs-324, Erasmus MC University Medical Centre, P.O Box 2040, 3000 CA Rotterdam, The Netherlands e-mail: jan.bakker@erasmusmc.nl Tel.: +31-10-4633629

Fax: +31-84-7506549

\section{Abstract Objective: Compare} duration of mechanical ventilation (MV), weaning time, ICU-LOS (ICULOS), efficacy and safety of remifentanil-based regimen with conventional sedation and analgesia. Design: Centre randomised, openlabel, crossover, 'real-life' study. Setting: 15 Dutch hospitals.

Patients: Adult medical and postsurgical ICU patients with anticipated short-term (2-3 days) MV. Interventions: Patient cohorts were randomised to remifentanil-based regimen $(n=96)$ with propofol as required, for a maximum of 10 days, or to conventional regimens $(n=109)$ of propofol, midazolam or lorazepam combined with fentanyl or morphine. Measurements and main results: Outcomes were weaning time, duration of MV, ICU-LOS, sedation- and analgesia levels, intensivist/ICU nurse satisfaction, adverse events, mean arterial pressure, heart rate. Median duration of ventilation (MV) was 5.1 days with conventional treatment versus 3.9 days with remifentanil (NS). The remifentanil-based regimen reduced median weaning time by $18.9 \mathrm{~h}$ $(P=0.0001)$. Median ICU-LOS was 7.9 days versus 5.9 days, respectively (NS). However, the treatment effects on duration of MV and ICU stay were time-dependent: patients were almost twice as likely to be extubated $(P=0.018)$ and discharged from the ICU $(P=0.05)$ on day $1-3$. Propofol doses were reduced by $20 \%$ $(P=0.05)$. Remifentanil also improved sedation-agitation scores $(P<0.0001)$ and intensivist/ICU nurse satisfaction $(P<0.0001)$. All other outcomes were comparable. Conclusions: In patients with an expected short-term duration of MV, remifentanil significantly improves sedation and agitation levels and reduces weaning time. This contributes to a shorter duration of MV and ICU-LOS.

Keywords Analgesia .

Intensive care .

Mechanical ventilation .

Remifentanil $\cdot$ Sedation $\cdot$ Weaning 


\section{Introduction}

The vast majority of patients admitted to the intensive care unit (ICU) receive both analgesic (opioid) and sedative agents to control pain, relieve agitation and anxiety, aid compliance with mechanical ventilation (MV), and hence overall, to help maintain comfort [1]. When administered over several days, the pharmacodynamic effects of conventional opioids such as fentanyl and morphine become unpredictable and are often prolonged as a result of re-distribution and accumulation [2]. This may increase the risk of suppressed respiratory drive and potentially delay weaning and extend the duration of MV.

Important levers to reduce the duration of MV are its well-known risks, including complications directly related to the process of intubation and MV such as injury to the trachea and to lung tissue, and complications caused by loss of airway defence mechanisms such as nosocomial pneumonia [3-5]. Reduction of the duration of MV may also yield savings in terms of reduced ICU and hospital length of stay and reduced costs [6]. It has further been suggested that from a patient's point of view, perhaps the most troubling aspects are the tube-associated discomfort and the compromised ability to eat and to communicate, contributing to feelings of powerlessness, isolation, and anxiety $[3,7]$.

Remifentanil is a selective $\mu$-opioid receptor agonist with a potency similar to fentanyl [8]. It has a rapid onset of action (blood-brain equilibration half-time $\approx 1 \mathrm{~min}$ ) and, unlike existing opioids, is metabolized in an organindependent fashion by non-specific esterases in the blood and tissues into an inactive metabolite [9]. This results in a short context sensitive half-time of approximately 4 min, without accumulation after prolonged infusion [10]. The rapid esterase metabolism provides a predictable pharmacokinetic profile, which is independent of the dose and duration of infusion and of the patient's renal or hepatic function $[10,11]$. Remifentanil's organ-independent metabolism and predictable pharmacokinetic profile allow that in a remifentanil-based analgesia and sedation regimen, the opioid is used as the main drug to provide patient comfort, while the use of the sedative agent is kept to a minimum.

Predicting the duration of MV and ICU stay can be difficult and the use of long-acting sedatives/analgesics in the early phase of ICU admission can prolong the duration of MV when a patient recovers more quickly than expected [12]. In such unpredictable circumstances, a short-acting agent may improve the speed of weaning, shorten the duration of MV, and advance ICU discharge. Therefore, we conducted a centre randomised, open-label, crossover study in a 'real-life' setting to compare the duration of MV, weaning time, ICU-LOS, efficacy, and safety of a remifentanil-based analgesia and sedation regimen to conventional sedation and analgesia regimens in a mixed group of medical and post-surgical ICU patients with anticipated short-term (2-3 days) MV following the start of the study medication. Preliminary results of this study were published as an abstract at the 2006 ESICM meeting [13].

\section{Materials and methods}

A description of the materials and methods of this study, including a graphical presentation of the study phases and assessments, is available as electronic supplementary material.

\section{Results}

\section{Patients}

Of 205 patients recruited at 15 medical centres (one of the planned centres did not participate in the study), 109 were randomised to receive the conventional sedation and analgesia regimen and 96 to receive the remifentanilbased analgesia and sedation regimen. Patient demographics and baseline characteristics of the groups were well-balanced (Table 1). The study medication usage and doses are summarized in Table 2. During the 10-day treatment period, $9(8 \%)$ patients in the conventional arm versus $25(26 \%)$ in the remifentanil arm were withdrawn for reasons other than decease $(P=0.001)$. These reasons were: practical problems not related to sedation or analgesia ( 1 vs. $10 \%)$, lack of efficacy ( 2 vs. $5 \%$ ), transferred outside the ICU (3 vs. 2\%), change in status of exclusion criteria ( 3 vs. $1 \%$ ), adverse events ( 0 vs. $2 \%$ ), withdrawal of consent ( 0 vs. $2 \%$ ), subjects detriment to continue in the study ( 0 vs. $1 \%)$ or other ( 0 vs. $3 \%)$. In addition, 15 patients in the conventional treatment group new switched to another analgesic or hypnotic agent during the treatment period without being withdrawn. In both study arms, half of the withdrawals occurred within the first 2 days of treatment. Eleven (10\%) patients in the conventional arm vs. $9(9 \%)$ in the remifentanil arm died on a study treatment day $(P=1.0)$, and $23(21 \%)$ patients in the conventional arm vs. $8(8 \%)$ in the remifentanil arm were still ventilated by the end of day $10(P=0.019)$ (Fig. 1).

\section{Primary end point}

The median duration of MV over the 10-day treatment period was 5.1 days (95\% confidence interval: $3.5,6.7)$ in the conventional arm vs. 3.9 days (95\% confidence interval: 2.6, 5.2) in the remifentanil arm (Fig. 2). As the 
Table 1 Patient demographics and baseline characteristics

\begin{tabular}{|c|c|c|c|}
\hline & $\begin{array}{l}\text { Conventional sedation } \\
\text { and analgesia regimen }\end{array}$ & $\begin{array}{l}\text { Remifentanil-based } \\
\text { analgesia and sedation } \\
\text { regimen }\end{array}$ & $P$ value \\
\hline Number of patients & 109 & 96 & \\
\hline Medical patients, $n(\%)$ & $69(63 \%)$ & $54(56 \%)$ & 0.32 \\
\hline Post-surgical patients, $n(\%)$ & $40(37 \%)$ & $42(44 \%)$ & \\
\hline Emergency & $18(45 \%)$ & $23(55 \%)$ & 0.51 \\
\hline Elective & $22(55 \%)$ & $19(45 \%)$ & \\
\hline \multicolumn{4}{|l|}{ Dx medical patients, $n(\%)$} \\
\hline Cardiovascular & $7(10 \%)$ & $7(13 \%)$ & 0.52 \\
\hline Respiratory & $46(67 \%)$ & $36(67 \%)$ & \\
\hline Gastrointestinal & $2(3 \%)$ & $2(4 \%)$ & \\
\hline Sepsis & $11(16 \%)$ & $4(7 \%)$ & \\
\hline Other & $3(4 \%)$ & $5(9 \%)$ & \\
\hline \multicolumn{4}{|l|}{ Dx surgical patients, $n(\%)$} \\
\hline Cardiovascular & $11(27.5 \%)$ & $15(36 \%)$ & 0.90 \\
\hline Respiratory & $2(5 \%)$ & $2(5 \%)$ & \\
\hline Gastrointestinal & $23(57.5 \%)$ & $22(52 \%)$ & \\
\hline Other & $4(10 \%)$ & $3(7 \%)$ & \\
\hline Age, mean years ${ }^{\mathrm{a}}$ & $64 \pm 14$ & $66 \pm 13$ & 0.53 \\
\hline Gender, \% male & $63 \%$ & $61 \%$ & 0.89 \\
\hline Weight, mean $\mathrm{kg}^{\mathrm{a}}$ & $80 \pm 14$ & $78 \pm 16$ & 0.30 \\
\hline SAPS II, mean score ${ }^{a}$ & $46 \pm 14$ & $44 \pm 16$ & 0.22 \\
\hline MAP, mean mm $\mathrm{Hg}^{\mathrm{a}}$ & $75 \pm 15$ & $80 \pm 19$ & 0.0028 \\
\hline $\mathrm{HR}$, mean $\mathrm{bpm}^{\mathrm{a}}$ & $96 \pm 23$ & $91 \pm 22$ & 0.80 \\
\hline SAS, mean score ${ }^{\mathrm{a}}$ & $2.2 \pm 1.3$ & $2.3 \pm 1.5$ & 0.87 \\
\hline PI, mean score ${ }^{\mathrm{a}}$ & $1.3 \pm 0.6$ & $1.4 \pm 1.0$ & 0.91 \\
\hline
\end{tabular}

$D x$ diagnosis; $H R$ heart rate, MAP mean arterial pressure, PI pain intensity, SAPS II simplified acute physiology scores, $S A S$ sedation-agitation scale

${ }^{a}$ Data are presented as mean \pm standard deviation

Differences in proportions between the groups were tested with the Chi-square test. Mean differences in the continuous variables were tested with the t-test except SAS and PI scores which were tested with the Mann-Whitney test

Table 2 Exposure to study medication

\begin{tabular}{|c|c|c|c|c|}
\hline & \multirow{2}{*}{$\begin{array}{l}\text { Proportion of patients using } \\
\text { the agent }(\%)^{\mathrm{a}}\end{array}$} & \multicolumn{2}{|l|}{ Bolus dose } & \multirow{2}{*}{$\begin{array}{l}\text { Infusion dose } \\
\text { Median dose } \\
\text { (in } n \text { patients used) }\end{array}$} \\
\hline & & Median dose ${ }^{b}$ & $\begin{array}{l}\text { Frequency per } 24 \mathrm{~h} \\
\text { (in } n \text { patients used) }\end{array}$ & \\
\hline \multicolumn{5}{|c|}{ Conventional sedation and analgesia regimen } \\
\hline Morphine & 58 & $0.05 \mathrm{mg} / \mathrm{kg}$ & $0.64(10)$ & $0.03 \mathrm{mg} / \mathrm{kg} / \mathrm{h}(63)$ \\
\hline Fentanyl & 38 & $0.92 \mu \mathrm{g} / \mathrm{kg}$ & $0.63(18)$ & $1.05 \mu \mathrm{g} / \mathrm{kg} / \mathrm{h}(38)$ \\
\hline Midazolam & 81 & $0.06 \mathrm{mg} / \mathrm{kg}$ & $0.64(39)$ & $0.07 \mathrm{mg} / \mathrm{kg} / \mathrm{h}(84)$ \\
\hline Propofol & 46 & $0.56 \mathrm{mg} / \mathrm{kg}$ & $0.61(19)$ & $1.43 \mathrm{mg} / \mathrm{kg} / \mathrm{h} \mathrm{(46)}$ \\
\hline Lorazepam & 7 & $0.03 \mathrm{mg} / \mathrm{kg}$ & $0.57(6)$ & $0.02 \mathrm{mg} / \mathrm{kg} / \mathrm{h}(6)$ \\
\hline \multicolumn{5}{|c|}{ Remifentanil-based analgesia and sedation regimen } \\
\hline Remifentanil & 100 & - & - & $9.0 \mu \mathrm{g} / \mathrm{kg} / \mathrm{h}(96)$ \\
\hline Propofol & 65 & $0.48 \mathrm{mg} / \mathrm{kg}$ & $1.64(50)$ & $1.15 \mathrm{mg} / \mathrm{kg} / \mathrm{h}(61)$ \\
\hline
\end{tabular}

${ }^{a}$ In the conventional arm $1 \%$ of the subjects used piritramide and $3 \%$ used sufentanil (protocol violations)

b Median time-weighted average dose per patient when used

treatment effect on the duration of $\mathrm{MV}$ was time dependent $(P=0.002)$, significance testing for the whole study treatment period was not valid with the Cox's proportional-hazards model. Therefore, the treatment period was split into 2 periods: day $1-3$ and day $4-10$. Patients in the remifentanil arm were 1.86 times more likely to be extubated on day $1-3$ of treatment than patients in the conventional arm $(95 \%$ confidence interval: $1.11,3.11 ; P=0.018)$. Based on this rate ratio of 1.86, the expected percentage of extubated patients on day 1 will increase from $8 \%$ with the conventional regimen to $14 \% \quad\left(=1-\mathrm{e}^{1.86 \times \ln (1-0.08)}\right)$ with the remifentanil-based regimen, on day 2 from 23 to $39 \%$, and on day 3 from 34 to $54 \%$. The percentages of extubated patients with the conventional regimen were taken from the Kaplan-Meier curve. No difference was observed for day 4-10 (rate ratio, 0.98; 95\% confidence interval: $0.47,2.04 ; P=0.951)$. 

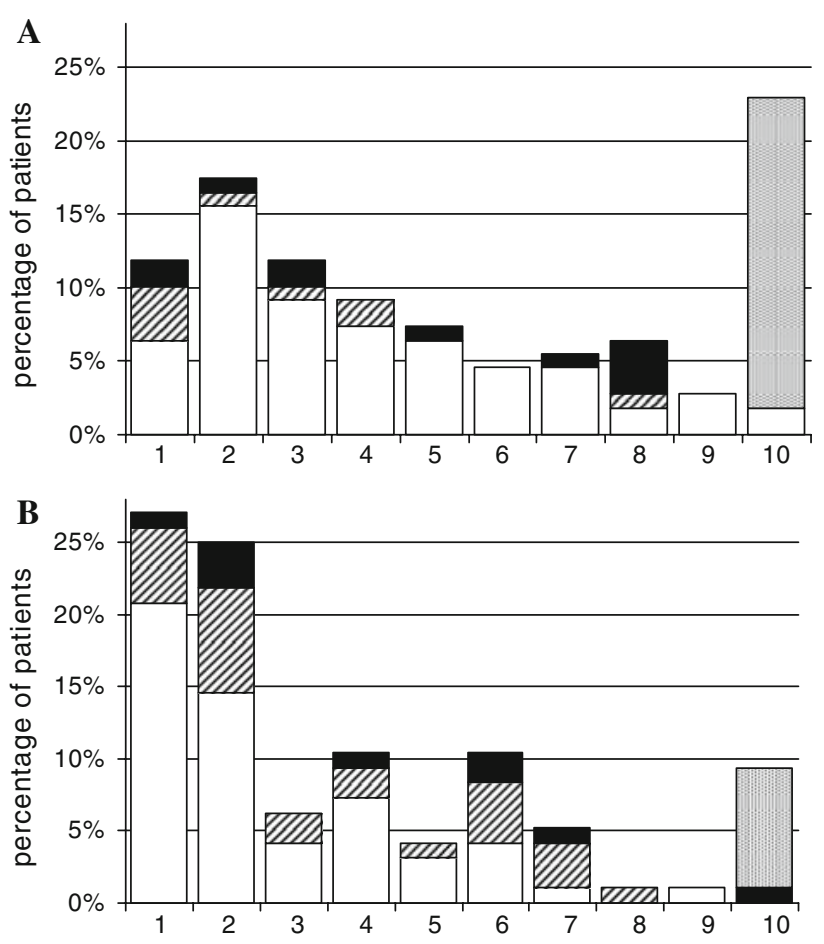

Fig. 1 Percentage of patients extubated, withdrawn, deceased, or still intubated by the end of day 10 . a Conventional sedation and analgesia regimen $(n=109)$. b Remifentanil-based analgesia and sedation regimen $(n=96)$. Unshaded areas extubated, stripped areas withdrawn, shaded areas deceased, dotted areas still intubated

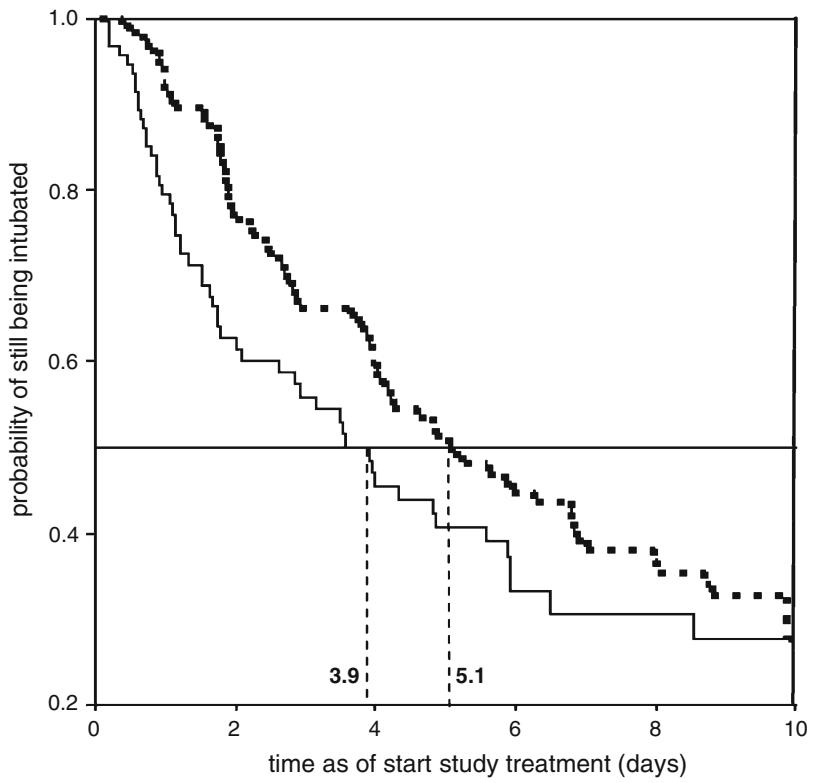

Fig. 2 Kaplan-Meier plot of the duration of mechanical ventilation (intention-to-treat population). Dotted curve conventional sedation and analgesia regimen, continuous curve Remifentanil-based analgesia and sedation regimen. $P$ value $(1-3$ days): $0.018, P$ value (4-10 days): 0.951
Secondary end points

The median weaning time was $24.8 \mathrm{~h}(95 \%$ confidence interval: $21.4,28.1$ ) in the conventional arm vs. $5.9 \mathrm{~h}$ (95\% confidence interval: $0.8,11.0$ ) in the remifentanil arm $(P=0.0001)$ (Fig. 3). The median ICU-LOS was 7.9 days $(95 \%$ confidence interval: $5.1,10.6)$ vs. 5.9 days (95\% confidence interval: $4.9,7.0$ ), respectively. Patients on remifentanil arm were 1.89 times more likely to be discharged from the ICU on day 1-3 of treatment than patients on conventional treatment (95\% confidence interval: $1.00,3.59 ; P=0.05)$. The 83 rd percentile value for ICU-LOS was 3.0 days for the conventional arm versus 1.8 days for the remifentanil arm. No difference was observed for day 4-28 (rate ratio, 1.14; 95\% confidence interval: $0.73,1.76 ; P=0.570)$.

The median time-weighted average infusion rates and bolus doses of the study drugs are reported in Table 2 . The infusion rate of propofol was $1.43 \mathrm{mg} / \mathrm{kg} / \mathrm{h}$ for those patients receiving propofol in the conventional treatment arm versus $1.15 \mathrm{mg} / \mathrm{kg} / \mathrm{h}$ for those in the remifentanilbased treatment group $(P=0.05)$.

In the remifentanil group, a total of 28 subjects received the following 41 episodes of post extubation medications: paracetamol 10, NSAID 1, piritramide 3, morphine 11 , bupivacaine 6 , fentanyl 2 , sufentanil 4 , clonidine 1 , midazolam 1, lorazepam 1 and oxazepam 1.

Patients in the remifentanil arm had consistently and significantly better SAS scores over the 10-day treatment period than patients in the conventional arm (mean weighted average $\pm \mathrm{SD}, \quad 3.3 \pm 0.9 \quad$ vs. $\quad 2.5 \pm 1.0$; $P<0.0001)$. PI scores did not significantly differ between the study arms (mean weighted average $\pm \mathrm{SD}, 1.3 \pm 0.5$ vs. $1.2 \pm 0.4 ; P=0.120$ ). The proportion of 'excellent'

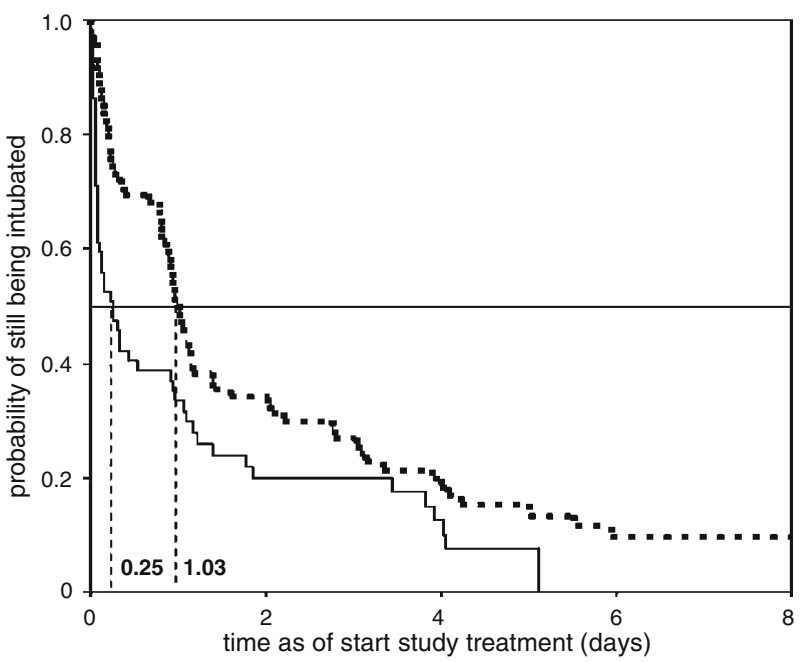

Fig. 3 Kaplan-Meier plot of the weaning time (intention-to-treat population). Dotted curve conventional sedation and analgesia regimen. Continuous curve remifentanil-based analgesia and sedation regimen. $P$ value: 0.0001 
Table 3 Intensivist and intensive care nurse satisfaction with analgesia, sedation, extubation, and ease of study drug usage (in $n$ patients assessed)

\begin{tabular}{|c|c|c|c|c|c|c|c|c|}
\hline & $\begin{array}{l}\mathrm{C} \\
\text { Analgesia }\end{array}$ & $\mathrm{R}$ & $\begin{array}{l}\mathrm{C} \\
\text { Sedation }\end{array}$ & $\mathrm{R}$ & $\begin{array}{l}\mathrm{C} \\
\text { Extubation }\end{array}$ & $\mathrm{R}$ & $\begin{array}{l}\mathrm{C} \\
\text { Usage comfor }\end{array}$ & $\mathrm{Rt}$ \\
\hline \multicolumn{9}{|l|}{ Intensivist satisfaction } \\
\hline Poor & $0 \%(0)$ & $3.1 \%(3)$ & $0.9 \%(1)$ & $8.3 \%(8)$ & $1.6 \%$ & $0 \%(0)$ & $0 \%(0)$ & $2.1 \%(2)$ \\
\hline Good/fair & $89 \%(97)$ & $52.1 \%(50)$ & $90.8 \%(99)$ & $62.5 \%(60)$ & $90.5 \%(57)$ & $55.5 \%(30)$ & $88.1 \%(96)$ & $67.7 \%(65)$ \\
\hline Excellent/very good & $11 \%(12)$ & $44.8 \%(43)$ & $8.3 \%(9)$ & $29.2 \%(28)$ & $7.9 \%(5)$ & $44.5 \%(24)$ & $11.9 \%(13)$ & $30.2 \%(29)$ \\
\hline$P$ value & $<0.0001$ & & 0.26 & & $<0.0001$ & & 0.31 & \\
\hline \multicolumn{9}{|c|}{ Intensive care nurse satisfaction } \\
\hline Poor & $0 \%(0)$ & $1 \%(1)$ & $0.9 \%(1)$ & $6.3 \%(6)$ & $1.6 \%(1)$ & $1.9 \%(1)$ & $0.9 \%(1)$ & $2.1 \%(2)$ \\
\hline Good/fair & $72.5 \%(79)$ & $56.3 \%(54)$ & $77.1 \%(84)$ & $66.6 \%(64)$ & $87.5 \%(56)$ & $62.9 \%(34)$ & $80.7 \%(88)$ & $71.8 \%(69)$ \\
\hline Excellent/very good & $27.5 \%(30)$ & $42.7 \%(41)$ & $22 \%(24)$ & $27.1 \%(26)$ & $10.9 \%(7)$ & $35.2 \%(19)$ & $18.4 \%(20)$ & $26.1 \%(25)$ \\
\hline$P$ value & 0.030 & & 0.25 & & 0.007 & & 0.80 & \\
\hline
\end{tabular}

$C$ conventional sedation and analgesia regimen, $R$ remifentanil-based analgesia and sedation regimen

Mann-Whitney test

and 'very good' intensivist and nurse satisfaction scores for patient analgesia and extubation was significantly higher with the remifentanil-based regimen compared to the conventional regimen $(P<0.0001)$ (Table 3$)$.

\section{Safety}

MAP and HR values were comparable between the study regimens over the 10-day treatment period. Mean timeweighted MAP was $79.4 \mathrm{~mm} \mathrm{Hg} \pm 12.1$ for remifentanil and $78.3 \mathrm{~mm} \mathrm{Hg} \pm 10.3$ for conventional treatment $(P=0.517)$. Mean time-weighted HR was $88.0 \mathrm{bpm} \pm$ 16.4 and $92.0 \mathrm{bpm} \pm 15.0$, respectively $(P=0.070)$. Twelve non-serious adverse events were observed in 6 patients $(6 \%)$ in the conventional arm and 6 non-serious adverse events in 6 patients $(6 \%)$ in the remifentanil arm $(P=0.481)$. Three of these events (hypotension, neuritis motor, and withdrawal syndrome) were considered related to remifentanil treatment. The patient with hypotension was withdrawn from the study medication. Eleven serious adverse events were observed in 10 patients (9\%) in the conventional arm and 13 serious adverse events in 10 patients $(10 \%)$ in the remifentanil arm $(P=0.612)$. None of these events were considered related to the study medication.

\section{Discussion}

This centre randomised, open-label, crossover study in a broad spectrum of mechanically ventilated patients showed that patients receiving a remifentanil-based analgesia and sedation regimen required a significantly shorter weaning time. As a result, they were almost twice as likely to be extubated and discharged from the ICU within the first 3 days of treatment compared to patients receiving a conventional sedation and analgesia regimen.

We chose an open-label design to allow comparison of techniques rather than treatments. A conventional sedation and analgesia regimen differs from a remifentanil-based analgesia and sedation regimen in terms of momentum and action of intervention. Because switching regularly between the regimens as in patient-randomised designs is difficult, a centre randomised, cross-over design was chosen. When all sites completed their first cohort of patients, they started enrolling an equal number of patients for the next cohort. This design precludes a possible time-effect and between-centre variability.

Remifentanil was administered for a maximum of 10 days, as safety and efficacy data on remifentanil use longer than 10 days were not available at the time of the start of patient enrolment. To our knowledge, only 3 previous studies have reported on prolonged infusion of remifentanil in an ICU setting [14-16].

The treatment effect for duration of MV and for ICULOS was time-dependent. The cut-off point for timedependency was set at 3 days, because we aimed at including patients who were expected to require shortterm (2-3 days) MV. Moreover, the safety and efficacy for longer treatment of ICU patients with remifentanil had not been fully established yet. Hence, current prescribing information does not recommend remifentanil in ICU patients for more than 3 days.

Whilst the patients in the remifentanil-based treatment group were almost twice as likely to be extubated within the first 3 days of treatment, no significant difference in the duration of MV was observed for the entire 10-day treatment period. Sixty percent of patients were still intubated after day 3 despite the inclusion criterion of an anticipated 2-3 days of MV. This caused the study to be underpowered. To date, three studies have shown a significant reduction in the duration of MV with remifentanil compared to conventional regimens [14, 17, 18], whereas 1 other did not [19]. For the day 4-10 treatment period, no significant difference was found whilst one would expect patients undergoing longer sedation to benefit even more due to the favourable pharmacokinetics of remifentanil. This can be explained by the high number of patients who 
were still intubated at day 10 (21\% of the patients in the conventional regimen patients versus $8 \%$ of the patients in the remifentanil-based regimen).

The shorter median weaning time in the remifentanil arm is probably directly related to remifentanil's pharmacokinetic profile. Three active comparator studies have also shown significant reductions in weaning time with remifentanil [14, 15, 18], whereas 1 other has not [20].

Patients in the remifentanil arm had a 1.89 higher chance of ICU discharge during the first 3 days of treatment. Previous studies showed mixed results: two studies found a significant reduction in ICU-LOS with remifentanil vs. conventional regimens $[17,18]$, whereas four others did not $[14,15,19,20]$. Discharge from ICU depends not only on treatment-related factors, but also on managerial factors, such as the availability of beds and staff, and time of the day.

The median time-weighted average infusion rate of remifentanil infusion was $9.0 \mu \mathrm{g} / \mathrm{kg} / \mathrm{h}$, which is well within the rates reported previously in ICU patients $[14,18,20]$ and the Summary of Product Characteristics of remifentanil (dose range, $0.4-45 \mu \mathrm{g} / \mathrm{kg} / \mathrm{h}$ ). The median time-weighted average infusion rate of propofol was $20 \%$ lower in the remifentanil arm compared to the conventional arm. This affirms remifentanil's sedative-sparing effect and is in keeping with previous clinical trials in ICU patients [14, 18, 20, 21]. The consistently better SAS scores in the remifentanil arm indicate that this agent is easier to titrate to optimal response than the conventional agents used in our study.

\section{Study strengths and limitations}

Our study was not blinded and is thus open to all usual criticism that applies to such studies. However, the results reflect the consequences of treating a broad population of medical and post-surgical patients in a 'real life' setting and by using the routine logistics of the investigational sites.

More patients in the conventional arm were still ventilated by the end of day 10. This finding is difficult to interpret, because the withdrawal rate in the remifentanil arm was higher than in the conventional arm and patients who were withdrawn were not followed up for MV details. The higher withdrawal rate with remifentanil may be explained by unfamiliarity with remifentanil and the fact that the conventional arm had more analgesia and sedation treatment options: any combination of fentanyl or morphine with either propofol, midazolam, or lorazepam was allowed. In fact, 15 patients in the conventional arm were switched to another hypnotic agent during the study treatment period. So, in both study groups a comparable number of patients changed their initial analgesia and sedation regimen.

The guidelines of the Dutch Society of Intensive Care specify the bolus and maintenance dose of drugs for analgesia and sedation. They do not include specific instructions for dose adjustments of analgesia and sedation like a daily interruption or a weaning protocol. In accordance with the Dutch guidelines, our study protocol did not include specific instructions for adjustments or weaning in both study arms. However, as our study demonstrated benefit of the remifentanil-based regimen over the first 3 days of treatment, the impact of daily interruptions in this short period may have been limited. In addition, the median duration of MV in the conventional arm (5.1 days) was comparable to that seen in the intervention arm with daily interruption in the study by Kress et al. (4.9 days) [22]. Whether the effect of a sedation protocol on ventilation time and ICU stay is more important than the choice of the analgesic- and sedative agent is questionable, but a recent study shows that improvement in weaning time can still be achieved with remifentanil on top of a daily interruption protocol [23].

\section{Study implications}

Our results have several medical and managerial implications. A shorter duration of MV has the potential to reduce complications associated with prolonged intubation and ventilation and to limit patient discomfort $[4,5]$. Once familiar with remifentanil, it is easy to titrate to response with limited use of sedative agents. A reduction in ICULOS increases ICU capacity in terms of beds and staff, reduces costs, and allows more flexible ICU bed management. Our study affirms that prediction of the duration of MV is difficult. Therefore, we propose to start patients on a remifentanil-based regimen whenever short-term MV is anticipated and to evaluate after 2-3 days of treatment. If at that point longer-term MV is anticipated, for example due to (increased risk of) complications, patients may be switched to conventional analgesics and sedatives.

\section{Conclusions}

We conclude that in patients with anticipated short-term duration of MV, a remifentanil-propofol analgo-sedation regimen provides better control of sedation and agitation and reduces weaning time compared to conventional regimens. In addition, patients on a remifentanil-propofol based regimen are almost twice as likely to be extubated and discharged from the ICU within the first 3 days of treatment than patients on conventional regimens. Both regimens are equally well tolerated.

Acknowledgments This study was designed in collaboration with Jan Bakker, MD, PhD, lead investigator (Erasmus MC University Medical Centre, Rotterdam, The Netherlands), and performed and funded by GlaxoSmithKline, Zeist, The Netherlands (GSK code: ULT101653, ClinicalTrials.gov Identifier: NTC001588). Statistical analysis was performed by the Department of Epidemiology and 
Biostatistics, Erasmus MC University Medical Centre, Rotterdam, The Netherlands.

Open Access This article is distributed under the terms of the Creative Commons Attribution Noncommercial License which permits any noncommercial use, distribution, and reproduction in any medium, provided the original author(s) and source are credited.

\section{Appendix}

On behalf of the other UltiSAFE investigators:

K. Polderman, MD, PhD, Free University Medical Centre, Amsterdam, The Netherlands
N. Fennema, MD, Kennemer Hospital, Haarlem, The Netherlands

C. J. G. M. Jacobs, MD, Elkerliek Hospital, Helmond, The Netherlands

J. C. Smid, MD, Medical Centre Twente, Hengelo, The Netherlands

A. van Gemert-Koopman, MD, PhD, Albert Schweitzer Hospital, Dordrecht, The Netherlands

A. D. van der Meer, MD, Catharina Hospital, Eindhoven, The Netherlands

D. J. Versluis, MD, PhD, Medical Centre Haaglanden, The Hague, The Netherlands

M. de Jong, MD, Medical Centre Alkmaar, Alkmaar, The Netherlands

\section{References}

1. Gravel NR, Searle NR, Sahab PG, Carrier M (1999) Sedation in critically ill patients: Practical recommendations. CNS Drugs 11:9-22

2. Egan TD, Lemmens HJ, Fiset $P$, Hermann DJ, Muir KT, Stanski DR, Shafer SL (1993) The pharmacokinetics of the new short-acting opioid remifentanil (GI87084B) in healthy adult male volunteers. Anesthesiology 79:881-892

3. Mehta S, Hill NS (2001) Noninvasive ventilation. Am J Respir Crit Care Med 163:540-577

4. Andrews P, Azoulay E, Antonelli M, Brochard L, Brun-Buisson C, De Backer D, Dobb G, Fagon J-Y, Gerlach H, Groeneveld J, Macrae D, Mancebo J, Metnitz P, Nava S, Pugin J, Pinsky M, Radermacher P, Richard C (2007) Year in review in intensive care medicine, 2006. II. Infections and sepsis, haemodynamics, elderly, invasive and noninvasive mechanical ventilation, weaning, ARDS. Intensive Care Med 33:214-229

5. Andrews P, Azoulay E, Antonelli M, Brochard L, Brun-Buisson C, Dobb G, Fagon J-Y, Gerlach H, Groeneveld J, Mancebo J, Metnitz P, Nava S, Pugin J, Pinsky M, Radermacher P, Richard C, Tasker R (2006) Year in review in intensive care medicine, 2005. II. Infection and sepsis, ventilatorassociated pneumonia, ethics, haematology and haemostasis, ICU organisation and scoring, brain injury. Intensive Care Med 32:380-390

6. Battershill AJ, Keating GM (2006) Remifentanil: A review of its analgesic and sedative use in the intensive care unit. Drugs 66:365-385
7. Criner GJ, Tzouanakis A, Kreimer DT (1994) Overview of improving tolerance of long-term mechanical ventilation. Crit Care Clin 10:845-866

8. James MK, Feldman PL, Schuster SV, Bilotta JM, Brackeen MF, Leighton HJ (1991) Opioid receptor activity of GI 87084B, a novel ultra-short acting analgesic, in isolated tissues. $\mathbf{J}$ Pharmacol Exp Ther 259:712-718

9. Westmoreland CL, Hoke JF, Sebel PS, Hug CC Jr, Muir KT (1993)

Pharmacokinetics of remifentanil (GI87084B) and its major metabolite (GI90291) in patients undergoing elective inpatient surgery.

Anesthesiology 79:893-903

10. Kapila A, Glass PS, Jacobs JR, Muir KT, Hermann DJ, Shiraishi M, Howell S, Smith RL (1995) Measured contextsensitive half-times of remifentanil and alfentanil. Anesthesiology 83:968-975

11. Michelsen LG, Hug CC Jr (1996) The pharmacokinetics of remifentanil. $\mathbf{J}$ Clin Anesth 8:679-682

12. Gusmao Vicente F, Polito Lomar F, Melot C, Vincent JL (2004) Can the experienced ICU physician predict ICU-LOS and outcome better than less experienced colleagues? Intensive Care Med 30:655-659

13. Bakker J, Mulder P (2006) Remifentanil shortens duration of mechanical ventilation and ICU stay. Intensive Care Med 32(Suppl 1):S86 (Abstract 0320)

14. Breen D, Karabinis A, Malbrain M, Morais R, Albrecht S, Jarnvig IL, Parkinson P, Kirkham AJ (2005) Decreased duration of mechanical ventilation when comparing analgesiabased sedation using remifentanil with standard hypnotic-based sedation for up to 10 days in intensive care unit patients: A randomised trial [ISRCTN47583497]. Crit Care 9:R200R210
15. Baillard C, Cohen Y, Le Toumelin P, Karoubi P, Hoang P, Ait Kaci F, Cupa M, Fosse JP (2005) Rémifentanilmidazolam versus sufentanilmidazolam pour la sédation prolongée en reanimation. [Remifentanilmidazolam compared to sufentanilmidazolam for ICU long-term sedation]. Ann Fr Anesth Reanim 24:480-486

16. Meurant F (2006) Remifentanil versus sufentanyl narco-sedation in a surgical and medical critical care unit with prevention of narcotic induced hyperalgesia: A randomized double blind study [abstract]. Crit Care 10(Suppl. 1):P437

17. Muellejans B, Matthey T, Scholpp J, Schill M (2006) Sedation in the intensive care unit with remifentanil/ propofol versus midazolam/fentanyl: A randomised, open-label,

pharmacoeconomic trial. Crit Care 10:R91

18. Dahaba AA, Grabner T, Rehak PH, List WF, Metzler H (2004) Remifentanil versus morphine analgesia and sedation for mechanically ventilated critically ill patients: A randomized double blind study. Anesthesiology 101:640-646

19. Howie MB, Cheng D, Newman MF, Pierce ET, Hogue C, Hillel Z, Bowdle TA, Bukenya D (2001) A randomized double-blinded multicentre comparison of remifentanil versus fentanyl when combined with isoflurane/propofol for early extubation in coronary artery bypass graft surgery. Anesth Analg 92:1084-1093 
20. Muellejans B, Lopez A, Cross MH, Bonome C, Morrison L, Kirkham AJ (2004) Remifentanil versus fentanyl for analgesia based sedation to provide patient comfort in the intensive care unit: A randomized, double-blind controlled trial [ISRCTN43755713]. Crit Care 8:R1-R11
21. Park G, Lane M, Rogers S, Bassett P (2007) A comparison of hypnotic and analgesic based sedation in a general intensive care unit. Br J Anaesth 98:7682

22. Kress JP, Pohlman AS, O'Connor MF, Hall JB (2000) Daily interruption of sedative infusions in critically ill patients undergoing mechanical ventilation. N Engl J Med 342:14711477
23. Belhadj Amor M, Ouezini R, Lamine K, Barakette M, Labbene I, Ferjani M (2007) Daily interruption of sedation in intensive care unit patients with renal impairment: remifentanil-midazolam compared to fentanyl-midazolam. Ann Fr Anesth Reanim 26:1041-1044 